\title{
Biophysical Conceptual Doxastic Errors in Arterial Hypertension in Surgical and Medical Management, in the Frame of Navier Stokes Equations
}

\author{
Mara Lamothe ${ }^{1, *}$, Nery Lamothe ${ }^{1}$, Daniel Lamothe ${ }^{2}$, Miguel Ahumada-Ayala ${ }^{3,4}$, Crisanto Castillo ${ }^{5}$, Alejandro Alonso Altamirano $^{6}$, \\ Zoraida Cazarin7, Octavio Rojas-Diaz ${ }^{8}$, Hector Mayoral ${ }^{9,10}$, and Alicia Diaz-del Bosque ${ }^{11}$ \\ ${ }^{1}$ División de Ciencias de la Salud, Medical Surgeon Career, Universidad Autónoma Metropolitana, Xochimilco, Mexico \\ ${ }^{2}$ Universidad Westhill, Escuela de Medicina, Mexico \\ ${ }^{3}$ Former Dean, La Salle University School of Medicine, Mexico \\ ${ }^{4}$ Emeritus Professor of Biochemistry and Medicine, La Salle University School of Medicine, Mexico \\ ${ }^{5}$ Full-time Professor of Mathematics and Researcher, Instituto Tecnológico y de Estudios Superiores de Monterrey, Mexico \\ ${ }^{6}$ Coordinator of Internship and Social Service of the Medical Surgeon Career, Full-time Professor and Researcher Universidad Autónoma \\ Metropolitana, Xochimilco, Mexico \\ ${ }^{7}$ Hospital "Darío Fernández Fierro, ISSSTE," Surgery Service, Mexico \\ ${ }^{8}$ The American British Cowdray Medical Center, Surgery Division, Fellow of the American College of Surgeons, Mexico \\ ${ }^{9}$ Professor of Internal Medicine, Universidad Autónoma Metropolitana, Mexico \\ ${ }^{10}$ Unidad de Posgrado, Universidad Nacional Autónoma de Mexico (UNAM), Mexico \\ ${ }^{11}$ Intensive Care Unit, Hospital 20 de Noviembre, ISSSTE, Mexico
}

*Corresponding authors: Mara Lamothe, División de Ciencias de la Salud, Medical Surgeon Career, Universidad Autónoma Metropolitana, Xochimilco, Mexico, E-mail: plamothe@lamothe.com

Received: 06 May, 2021 | Accepted: 13 Jun, 2021 | Published: 04 Jul, 2021

Citation: Lamothe M, Lamothe N, Lamothe D, Ahumada-Ayala M, Castillo C, et al. (2021) Biophysical Conceptual Doxastic Errors in Arterial Hypertension in Surgical and Medical Management, in the Frame of Navier Stokes Equations. J Clin Case Stu 6(2): dx.doi.org/10.16966/24714925.223

Copyright: (c) 2021 Lamothe M, et al. This is an open-access article distributed under the terms of the Creative Commons Attribution License, which permits unrestricted use, distribution, and reproduction in any medium, provided the original author and source are credited.

\begin{abstract}
Multiple tragic biophysical errors in relation to hypertension in surgery and medicine, constitute conceptual atrocities: 1) Many physicians believe that perfusion decays with the fourth power of the radius, which is the result of a doxastic misunderstanding of the Poiseuille equation. These phenomena are even more transcendent in the case of surgical situations when the homeostatic metastability is more critical and with less margin to be compensated. 2) Furthermore, when seen the occlusion of an artery, frequently, instead of measuring the radius, they measure the apparent cross-sectional area. 3) By reducing the driving pressure with antihypertensive drugs, we are decreasing axial pressure in the flow and consequently the perfusion. 4) The sphygmomanometer measures transmural pressure and not driving pressure which is what produces perfusion. 5) The main hemodynamic cause of damage is not transmural hypertension but Laplacian tension. 6) The damage to the arteries does not depend on transmural pressure but on the energy density per time, in units of Joules per cubic meter per second, or Watts per cubic meter. 7) Hypertension, ceteris parivus, increases perfusion. 8) The baroreceptors do not respond to transmural pressure but to Laplacian arterial tension. 9) The brain and the heart have self-regulation of their perfusion, but vasodilators increase perfusion in other tissues, reducing cerebral and coronary perfusion due to the stolen effect. 10). Strictly, all gradients constitute potential energy, as happens in the instances of the concentration gradients, temperature gradients, pressure gradients, and electrical gradients. 11) The derivative of pressure with respect to time, that is the change in pressure due to change in time, is the derivative of the work per volume per time (change in work density due to time), that is, power density. 12) What determines the perfusion is the axial gradient, not of pressure but energy. 13) Hyperbolically if we consider taking the pressure of a pachyderm, we would obtain readings significantly higher. 14) Pressure is, in reality, energy density, which means, energy per infinitesimal unit of volume. 15) The venous return consists of the blood flow returning to the right heart. Because the input of the right side must equal its output, then in the steady-state situation, the cardiac outputs of the right and left sides are essentially equal. Consequently, the systemic venous return matches the systemic cardiac output. The venous return should be equal to or less than the cardiac output. The heart, as a pump, cannot expel a volume that has not been received; notwithstanding, in the case of valve regurgitation, the heart can expel a fraction of the venous return twice. The clinical physician should ask himself or herself: Is the preload volume in the EDV or the pressure at the time of the EDV which has been diminished before starting the isovolumic contraction?
\end{abstract}

\section{Prolegomena as Formal Introduction}

Ignorance of the disquisitions analyzed here causes at least fifteen types of atrocities in the diagnosis and management of the so-called arterial hypertension, in the clinical, but especially in the surgical settings. Regarding the mathematical aspects, the reader can, if he is an expert, verify that they correspond to his knowledge; if not, on first reading he can conditionally accept the mathematical results and continue; so that, at another time, more calmly, he can review the 
mathematical foundations, which are here to give light to the concepts and not as aesthetic elements. Strictly, the appropriate approach is the application of the Popperian procedure, taking the mathematical logically apodictic results as protocol sentences or clauses [1]; considering them in a conditional logic: if the mathematical inferences are consistent, without contradictions; then, the physiological and clinical atrocities are demonstrated. The biophysical behavior of the cardiovascular system obeys the underlying biophysical laws.

Typically, the function to be optimized is to decrease the impact at a short, medium, and large term of hypertension [2]; in contrast, the function to be optimized in most surgical patients is to get adequate perfusion and oxygenation to the brain, heart, etc. during the surgery and in the perioperative time, e.g., avoiding hemodilution and low hemoglobin saturation, etc.

Besides optimizing the surgical repair, it is paramount to avoid the calamities of hypoxia and ischemia to which the surgical patient is especially prone. These surgical instances are not the appropriate moment to think in preventing neither hyaline arteriolosclerosis nor concentric hypertrophy of the left ventricle due to increased afterload pressure. Regarding arterial pressure, attention should focus on oxygen availability for the mitochondria and perfusion. The application of mathematical models according to a function to be optimized is representative of more mathematical-based approaches to complex biological problems [3-8].

The belief in an ideal eutrophic perfusion model is fallacious. Evolution is random variation and selection of genotypes through their phenotypes in terms of the reproductive success of their selfish genes, which generates extreme redundancy. The above is not an ideological position, but a phenomenological description of the evolution of the genes. In contrast to this, we can read the doxastic logic and the desiderative logic in the great texts as is the case in the following example [9]: "The morphology and local regulatory mechanisms of the microcirculation are designed to meet the particular needs of each tissue" [10]. Also taken from the most respected textbook of cardiology, "Braunwald's Heart Disease", in the chapter on hypertension, you can read: "the endothelial lining of blood vessels is critical to vascular health and constitutes a mayor defense against hypertension" $[2,11]$.

This corresponds to extreme teleology!!! Byological estructures are not designed.

Derivative of pressure in time:

$$
\frac{d P}{d t}=\frac{\left(\frac{N}{m^{2}}\right)}{\sec }=\frac{N}{m^{2} \sec }\left(\frac{m}{m}\right)=\frac{\text { Joul }}{m^{3} \sec }=\frac{\text { Watt }}{m^{3}}=\frac{\text { Power }}{\text { Volume }}
$$

The pressure that is considered in this equation corresponds to the driving or axial pressure, which is the gradient of two different points in the vessel, therefore absolutely different from transmural pressure. It is the power per unit area [12] that generates instantaneous Laplacian tension; therefore, catastrophically producing hemorrhagic rupture of vessels, hyaline arteriolosclerosis, hyperplastic arteriolosclerosis, and endothelial physical damage. All these are because the system behaves catastrophically as predicted by the mathematical theory of catastrophes (Thorne) as explained in this paper. This is opposed to the operational belief that it is transmural pressure, measured by a sphygmomanometer as a surrogate.

Developing insight intuition over the pragmatically meaning of energy with two scandalous beef examples:

If we could convert thoroughly $115 \mathrm{gr}$ of butter into energy, and use it without any loss, we can elevate a $500 \mathrm{Kg}$ cow on the tip of the Burj
Khalifa, the highest building in the world with 154 floors (828 meters).

Now we can use the very same cow, as an example, to show how the energy possessed by its flesh if converted thoroughly without any loss, could have solved the problem of the ship stoked in the Suez Channel. Let's believe in this example to the BBC News, April 3, 2021: The 220,000-tonne Ever Given was finally freed. Nobody has to believe it, just follow the Physical foundations and do the math. Here are the demonstrations:

$$
\begin{aligned}
& \mathrm{PE}=\mathrm{mgh} \\
& 115 \mathrm{gr}\left(9 \frac{\mathrm{c}}{g r}\right) \times 10^{3}=500 \mathrm{~kg}\left(9.8 \frac{\mathrm{m}}{\mathrm{sec}^{2}}\right) \mathrm{h} \\
& 1,035 \times 10^{3} \mathrm{c}\left(4 \frac{\mathrm{J}}{\mathrm{c}}\right)=(4,900 \mathrm{~N}) \mathrm{h} \\
& h=\frac{4 \times 10^{6} \mathrm{~J}}{5,00 \mathrm{~N}}=828 \mathrm{~m} \\
& E=200,000 \operatorname{gr}\left(1 \frac{\mathrm{c}}{g r}\right) \times 10^{3}+70,000 \mathrm{gr}\left(9 \frac{\mathrm{c}}{g r}\right) \times 10^{3}=830 \times 10^{6} \mathrm{C} \\
& E=830 \times 10^{6} \mathrm{c}\left(4 \frac{\mathrm{J}}{\mathrm{c}}\right)=3.32 \times 10^{9} \mathrm{~J} \\
& P E=m g h \\
& 3.32 \times 10^{9} \mathrm{~J}=220 \times 10^{6} \mathrm{Kg}\left(9.8 \frac{\mathrm{m}}{\mathrm{sec}^{2}}\right) h \\
& h=\frac{3.32 \times 10^{9} \mathrm{~J}}{2.20 \times 10^{9} \mathrm{~N}}=1.5 \mathrm{~m}
\end{aligned}
$$

This means that chemical potential energy that our hypothetical cow possess is, without losses, theoretically enough to lift the ever given ship to 1.5 meters above the ground without the buoyancy help of the water.

The cardiovascular system constitutes simultaneously a diversity of entities. First of all, it is a meta-topological structure that varies according to time and also depending on the organizational level, in terms of the General Systems Theory of von Bertalanffy [13].

Kidney participation in the so-called control of arterial pressure makes evident the wrong interpretation of the arterial pressure. While the physician measures the transmural pressure in a point of the artery, which among other things means he does not get the measure of the gradient between two points, since this correspond to the driving pressure, the baroreceptors in blood vessels and also the juxtaglomerular cells of the nephron respond to arterial distention and not to transmural pressure.

The synthesis and secretion of renin, an acid protease enzyme, mainly responsible of the control of blood perfusion and blood volume $[10,11]$.

The granules of the granular (juxtaglomerular) cells contain renin, an aspartyl protease, which is synthesized, stored, and released into the bloodstream. In the blood, the enzyme renin catalyzes the hydrolysis of angiotensinogen, a circulating alfa- 2 globulin, to produce angiotensin I, a decapeptide $[10,11]$.

Since the small solutes in the plasma and interstitial fluid exchange freely across the capillary wall, the entire ECF constitutes a single metatopological volume. The changes in the extracellular volume produce concomitant changes in the plasma volume. Thus, such an increase in plasma volume will directly produce an elevation in transmural blood pressure [10].

The parameter that the body controls in the intermediate- and longterm regulation of the mean arterial pressure is the effective circulating 
volume. The effective circulating volume is not an anatomical volume but the functional blood volume that reflects the extent of tissue perfusion, as sensed by the distension of the vessels [10].

Extracellular fluid volume receptors: Some are vascular sensors, among those functioning at high pressure are the juxtaglomerular apparatus at the renal afferent together with the carotid sinus and the aortic arch. At low pressure, there are receptors at the cardiac atria and in the pulmonary vasculature sensors in the central nervous system and in the liver $[10,11]$.

The kidney responds continuously to distension while the physician responds every time the patient has an appointment with him, to transmural pressure as measured by the sphygmomanometer.

Conceptually, it is closer to the reality to conceive that the kidney has an homeostatic mechanism that tends to control perfusion. Transmural pressure has no effect over the kidney.

It is well known and evident that a diminished flux in the renal artery will make the kidney liberate renin as if the kidney would measure the general perfusion from its own perfusion. However, the physician proceeds in an analog manner, as if the transmural pressure measurement is done every three months were a better measure of the general perfusion. The physician proceeds according to evidencebased medicine, which is not physiology, biophysics, biochemistry, or mathematical logic. It does not have to be teleological allegories as it is often the case as if the parts of the body would have been designed for doing what they do. As an example, from the best-known text of pathology we extract:

What is a human, but an ingenious machine designed to turn, with "infinite artfulness, the red wine of Shiraz into urine?" So said the storyteller in isak dinesen's seven gothic tales. More accurately but less poetically, human kidneys serve to convert more than $1700 \mathrm{~L}$ of blood per day into about $1 \mathrm{~L}$ of a highly concentrated fluid called urine. The physiologic mechanisms that the kidney has developed require a high degree of structural complexity [16].

Approximately $46 \%$ of individuals in the general population are hypertensive [16].

When the baroreceptor in the afferent arteriole senses decreased stretch, it directs neighboring juxtaglomerular cells to increase the release of renin into the circulation [10].

ANG II stimulates aldosterone release from the glomerulosa cells in the adrenal cortex. Furthermore, the homeostatic response tends to increase the perfusion and to diminish the energy density per time. All these considerations in no manner deny the fact that the surrogate of the transmural determination by the sphygmomanometer by the physician has transcendental implications for the health of the patient. This should not make anybody believe that he understands the fluid dynamics that obey Navier-Stokes, Einstein`s, Poiseuille`s, and Bernoulli 's equations or the microscales of Kolmogorov.

Thus in terms of the optimization process for non-polynomial problems, the function to be optimized is perfusion with the minimum energy density per time, which is evidently distinct from keeping transmural pressure below a certain arbitrary limit that could be systolic blood pressure of 120 and diastolic blood pressure of 80 . We keep things as simple as possible but not simpler than that. The participation of the kidney in the homeostatic control of the hemodynamics of the meta-topological cardiovascular system could be separated into the effects in the extracellular fluid and the effect of the renin-angiotensin-aldosterone system.
It seems that the so-called blood arterial control aids to prolong life without considering the perfusion of the main organ, the brain. Often, it is when the patient has orthostatic low pressure when it is considered that it might be the result of the drug.

Every homeostatic mechanism has evolved because it improves the reproductive success of the genes, which is almost absolutely different from the definition of the World Health Organization but also totally different from the normal tendency of applied medicine. The physician rarely has in mind that the effect of successful medicine increases the prevalence of diseases in the population which is a very well-known effect among public health scientists.

Hypertension as defined clinically is a measure of transmural pressures. The perfusion to the organs depend on the driving pressure and not the transmural pressure; even more, what damage the vessel is energy density per time, vascular Laplacian tension, which is pressure times the radius of the vessel.

Homeostatic perfusion response is a function of driving pressure, while the whole management of hypertension is a function of the transmural pressure.

Convective, diffusive, thermodynamic analysis should be applied to partially comprehend the nonpolynomial problem of perfusion, the subrogate of arterial pressure, and the biophysical consequences of acting accordingly in the surgical and clinical settings.

Poiseuille's and Bernoulli's equations are instances of the Navier Stokes equations and as such are considered in the present work [14].

The convective process of filtration and absorption, classically modeled according to Starling, has been improved by Pappenheimer, and now, a revised model has emerged, isolating the subglycocalyx fluid and its space [10].

On the other hand, the Fick's equation has been subsumed in the Navier Stokes equations [15]

\section{Disquisitions and Apodictic Equations Transforma- tions}

\section{Convective disquisitions}

The cardiovascular system has three convective loops: The transport of blood, the filtration absorption through the capillary wall, and the lymphatic circulation [7].

Convection enlarges the gradient, increasing diffusion because, thermodynamically, blood on the one hand and atmospheric air on the other, practically behave as quasi-infinite reservoirs [13].

At the capillary level, diffusion is carried out, obeying Starling's law of equilibrium, but convection is a process of fluid mechanics that obeys the Navier-Stokes equations, which we integrate with respect to distance, in all terms, so they are transformed from units of force/ volume to energy/volume.

Disquisitions over the Navier-Stokes Equations, Dimensional Analysis of the Navier-Stokes Equations [12].

$$
\begin{aligned}
& \mathrm{u}=\mathrm{velocity} \text { in } \mathrm{x} \text { direction } \\
& \mathrm{v}=\text { velocity in } \mathrm{y} \text { direction } \\
& \mathrm{w}=\mathrm{velocity} \text { in } \mathrm{z} \text { direction } \\
& \mathrm{u}, \mathrm{v} \text {, and } \mathrm{w} \text { depend on time, } \mathrm{x}, \mathrm{y} \text {, and } \mathrm{z} \text { directions. } \\
& \mathrm{u}(\mathrm{t}, \mathrm{x}, \mathrm{y}, \mathrm{z}), \mathrm{v}((\mathrm{t}, \mathrm{x}, \mathrm{y}, \mathrm{z}), \mathrm{w}(\mathrm{t}, \mathrm{x}, \mathrm{y}, \mathrm{z}))
\end{aligned}
$$


$a_{x}=\frac{d u}{d t}=\frac{\partial u}{\partial t}+\frac{\partial u}{\partial x} \frac{\partial x}{\partial t}+\frac{\partial u}{\partial y} \frac{\partial y}{\partial t}+\frac{\partial u}{\partial z} \frac{\partial z}{\partial t}=\frac{\partial u}{\partial t}+u \frac{\partial u}{\partial y}+w \frac{\partial u}{\partial z}$

$a_{y}=\frac{d v}{d t}=\frac{\partial v}{\partial t}+\frac{\partial v}{\partial x} \frac{\partial x}{\partial t}+\frac{\partial v}{\partial y} \frac{\partial y}{\partial t}+\frac{\partial v}{\partial z} \frac{\partial z}{\partial t}=\frac{\partial v}{\partial t}+u \frac{\partial v}{\partial y}+w \frac{\partial v}{\partial z}$

$a_{z}=\frac{d w}{d t}=\frac{\partial w}{\partial t}+\frac{\partial u}{\partial x} \frac{\partial x}{\partial t}+\frac{\partial w}{\partial y} \frac{\partial y}{\partial t}+\frac{\partial w}{\partial z} \frac{\partial z}{\partial t}=\frac{\partial w}{\partial t}+u \frac{\partial w}{\partial y}+w \frac{\partial w}{\partial z}$

$\rho\left(\frac{\partial u}{\partial t}+u \frac{\partial u}{\partial x}+v \frac{\partial u}{\partial y}+w \frac{\partial u}{\partial z}\right)=\rho g_{x}-\frac{\partial P}{\partial x}+\mu\left(\frac{\partial^{2} u}{\partial x^{2}}+\frac{\partial^{2} u}{\partial y^{2}}+\frac{\partial^{2} u}{\partial z^{2}}\right)$

$\rho\left(\frac{\partial v}{\partial t}+u \frac{\partial v}{\partial x}+v \frac{\partial v}{\partial y}+w \frac{\partial v}{\partial z}\right)=\rho g_{y}-\frac{\partial P}{\partial y}+\mu\left(\frac{\partial^{2} v}{\partial x^{2}}+\frac{\partial^{2} v}{\partial y^{2}}+\frac{\partial^{2} v}{\partial z^{2}}\right)$

$\rho\left(\frac{\partial w}{\partial t}+u \frac{\partial w}{\partial x}+v \frac{\partial w}{\partial y}+w \frac{\partial w}{\partial z}\right)=\rho g_{z}-\frac{\partial P}{\partial z}+\mu\left(\frac{\partial^{2} w}{\partial x^{2}}+\frac{\partial^{2} w}{\partial y^{2}}+\frac{\partial^{2} w}{\partial z^{2}}\right)$

$\rho \frac{d v}{d t}=-\nabla P+p g+\mu \nabla^{2} v$

$\frac{K g}{m^{3}} \frac{\left(\frac{m}{\operatorname{seg}}\right)}{\sec }=\frac{K g}{m^{3}} \frac{m}{\sec ^{2}}=\frac{N}{m^{3}}$

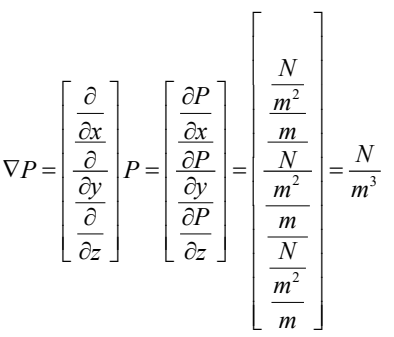

$p g=\frac{K g}{m^{3}} \frac{m}{\sec ^{2}}=\frac{N}{m^{3}}$

pascal seg $\frac{m}{\operatorname{seg}}=\left[\begin{array}{l}\frac{\partial^{2}}{\frac{\partial x^{2}}{\partial^{2}}} \\ \frac{\partial y^{2}}{\frac{\partial^{2}}{\partial z^{2}}}\end{array}\right] v=\frac{N}{m^{2}} \sec \left[\begin{array}{l}\frac{\partial^{2} v}{\frac{\partial x^{2}}{\partial^{2} v}} \\ \frac{\partial y^{2}}{\frac{\partial^{2} v}{\partial z^{2}}}\end{array}\right]=\frac{N}{m^{2}} \sec \left[\begin{array}{l}\frac{\left(\frac{m}{\mathrm{sec}}\right)}{\frac{m^{2}}{m}} \\ \frac{\left.\frac{m}{\mathrm{sec}}\right)}{\frac{m^{2}}{\left(\frac{m}{\mathrm{sec}}\right)}}\end{array}\right]=\frac{N}{m^{2}} \sec \left[\frac{\frac{1}{m \mathrm{sec}}}{\frac{1}{\frac{m \mathrm{sec}}{1}}}\right]=\frac{N}{m^{3}}$

\section{Dimensional analysis}

Let's look each term of the first equation, since the units corresponding to each term are going to be the same for the three equations.

The first term on the left side of the equation is density ( $\rho$ in units of $\left.\frac{K g}{m^{3}}\right)$ times the partial derivative of the velocity in the $\mathrm{x}$ direction with respect to time $\left(\frac{\partial u}{\partial t}\right.$ in units of $\left.\frac{\frac{m}{\sec }}{\sec }=\frac{m}{\sec ^{2}}\right)$ which give us $\frac{N}{m^{3}}$, which are units of force per volume.

$\rho\left(\frac{\partial u}{\partial t}\right)=\left(\frac{\mathrm{kg}}{\mathrm{m}^{3}}\right)\left(\frac{\frac{\mathrm{m}}{\mathrm{sec}}}{\mathrm{sec}}\right)=\left(\frac{\mathrm{kg}}{\mathrm{m}^{3}}\right) \frac{\mathrm{m}}{\mathrm{sec}^{2}}=\frac{\mathrm{N}}{\mathrm{m}^{3}}=$ units of force $=\frac{F}{V}$
Second, third and fourth terms of the left side of the equation: density ( $\rho$ in units of $\frac{K g}{m^{3}}$ ) times velocity in the $\mathrm{x}$ direction $(\mathrm{u}$ in units of $\frac{m}{\sec }$ ) times the partial derivative of velocity in $\mathrm{x}$ direction with respect to the $\mathrm{x}, \mathrm{y}$ or $\mathrm{z}$ direction $\left(\frac{\partial u}{\partial x}, \frac{\partial u}{\partial y}, \frac{\partial u}{\partial z}\right.$ in units of $\frac{\left(\frac{m}{\mathrm{sec}}\right)}{m}$, this is

$\left(\frac{K g}{m^{3}}\right)\left(\frac{m}{\mathrm{sec}}\right)\left(\frac{\left(\frac{m}{\mathrm{sec}}\right)}{m}\right.$ or $\frac{N}{m^{3}}$, again, units of force per volume.

$\rho\left(\frac{\partial u}{\partial t}\right)=\left(\frac{\mathrm{kg}}{\mathrm{m}^{3}}\right)\left(\frac{\frac{m}{\mathrm{sec}}}{\mathrm{sec}}\right)=\left(\frac{\mathrm{kg}}{\mathrm{m}^{3}}\right) \frac{m}{\mathrm{sec}^{2}}=\frac{N}{\mathrm{~m}^{3}}=$ units of force $=\frac{F}{V}$

First term of the right side of the equation: density ( $\rho$ in units of $\frac{K g}{m^{3}}$ ) times gravity acceleration in the $\mathrm{x}$ direction ( $g x$ in units of $\left.\frac{m}{\sec ^{2}}\right)$, which are unit of $\left(\frac{K g}{m^{3}}\right)\left(\frac{m}{\sec ^{2}}\right)$ or $\frac{N}{m^{3}}$, once again units of force per volume.

$\rho g_{x}=\left(\frac{k g}{m^{3}}\right)\left(\frac{m}{\sec ^{2}}\right)=\frac{N}{m^{3}}=$ units of force $=\frac{F}{V}$

Second term of the right side of the equation: the derivative of pressure whit respect $\mathrm{x}$ in unit of $\frac{\left(\frac{N}{m^{3}}\right)}{m}=\frac{N}{m^{3}}$ or units of force per volume.

$$
\frac{\partial P}{\partial x}=\frac{\left(\frac{N}{m^{2}}\right)}{m}=\frac{N}{m^{3}}=\text { units of force }=\frac{F}{V}
$$

The third term of the right side of the equation has units of viscosity ( $\mu$ units of Pascal $\times$ sec) times the second derivative of velocity with respect to distance $\left(\frac{\partial^{2} u}{\partial x^{2}}\right.$ in unis of $\left.\frac{\left(\frac{m}{\sec }\right)}{m^{2}}\right)$, units of (Pascal $x$ sec) $\frac{\left(\frac{m}{\mathrm{sec}}\right)}{m^{2}}$ or $\frac{N}{m^{3}}$, which are units of force per volume.

$\mu\left(\frac{\partial^{2} u}{\partial x^{2}}=(\right.$ pascal $\sec ) \frac{\left(\frac{m}{\sec }\right)}{m^{2}}=\left(\frac{N}{m^{3}} \sec \right) \frac{m}{m^{2} \sec }=\frac{N}{m^{3}}=$ units of force $=\frac{F}{V}$

We have seen that the units of the Navier-Stokes equation are in terms of force per cubic meter, if now we integrate both sides of each one of the three equations with respect to $\mathrm{dx}$, dy or $\mathrm{dz}$, respectively, the units will be force per cubic meter, times meter which is energy per cubic meter, that are units of energy density [12].

$\int \rho\left(\frac{\partial u}{\partial t}+u \frac{\partial u}{\partial x}+v \frac{\partial u}{\partial y}+w \frac{\partial u}{\partial z}\right) \mathrm{dx}=\int\left[\rho g_{x}-\frac{\partial P}{\partial x}+\mu\left(\frac{\partial^{2} u}{\partial x^{2}}+\frac{\partial^{2} u}{\partial y^{2}}+\frac{\partial^{2} u}{\partial z^{2}}\right)\right] \mathrm{dx}=\frac{N}{m^{2}}=\frac{J}{m^{3}}$ units of $\mathrm{p}_{\mathrm{x}}$ or energy per cubic meter

$\int \rho\left(\frac{\partial v}{\partial t}+u \frac{\partial v}{\partial x}+v \frac{\partial v}{\partial y}+w \frac{\partial v}{\partial z}\right) \mathrm{dy}=\int\left[\rho g_{y}-\frac{\partial P}{\partial y}+\mu\left(\frac{\partial^{2} v}{\partial x^{2}}+\frac{\partial^{2} v}{\partial y^{2}}+\frac{\partial^{2} v}{\partial z^{2}}\right)\right] \mathrm{dy}=\frac{N}{m^{2}}=\frac{J}{m^{3}}$ units of $\mathrm{p}_{\mathrm{y}}$ or energy per cubic meter 
$\int \rho\left(\frac{\partial w}{\partial t}+u \frac{\partial w}{\partial x}+v \frac{\partial w}{\partial y}+w \frac{\partial w}{\partial z}\right) \mathrm{d} z=\int\left[\rho g_{z}-\frac{\partial P}{\partial z}+\mu\left(\frac{\partial^{2} w}{\partial x^{2}}+\frac{\partial^{2} w}{\partial y^{2}}+\frac{\partial^{2} w}{\partial z^{2}}\right)\right] \mathrm{d} z=\frac{N}{m^{2}}=\frac{J}{m^{3}}$ units of $\mathrm{p}_{\mathrm{z}}$

If we do iterative integration with respect to $d x$, dy and $d z$, we get units of force per cubic meter times meter, times meter, times meter or force units:

$$
\iiint \rho\left(\frac{\partial u}{\partial t}+u \frac{\partial u}{\partial x}+v \frac{\partial u}{\partial y}+w \frac{\partial u}{\partial z}\right) \mathrm{dxdydz}=\iiint\left[\rho g_{x}-\frac{\partial P}{\partial x}+\mu\left(\frac{\partial^{2} u}{\partial x^{2}}+\frac{\partial^{2} u}{\partial y^{2}}+\frac{\partial^{2} u}{\partial z^{2}}\right)\right] \mathrm{dxdyd}=\mathrm{N}
$$

=units of force

$$
\iiint \rho\left(\frac{\partial v}{\partial t}+u \frac{\partial v}{\partial x}+v \frac{\partial v}{\partial y}+w \frac{\partial v}{\partial z}\right) \mathrm{dxdyd}=\iiint\left[\rho g_{y}-\frac{\partial P}{\partial y}+\mu\left(\frac{\partial^{2} v}{\partial x^{2}}+\frac{\partial^{2} v}{\partial y^{2}}+\frac{\partial^{2} v}{\partial z^{2}}\right)\right] \mathrm{dxdyd}=\mathrm{N}
$$

$=$ units of force

$$
\iiint \rho\left(\frac{\partial w}{\partial t}+u \frac{\partial w}{\partial x}+v \frac{\partial w}{\partial y}+w \frac{\partial w}{\partial z}\right) \mathrm{dxdyd}=\iiint\left[\rho g_{z}-\frac{\partial P}{\partial z}+\mu\left(\frac{\partial^{2} w}{\partial x^{2}}+\frac{\partial^{2} w}{\partial y^{2}}+\frac{\partial^{2} w}{\partial z^{2}}\right)\right] \mathrm{dxdyd}=\mathrm{N}
$$

$=$ units of force

\section{Conservation of momentum}

Now we integrate both sides of the previous equation with respect to time and we get units of force times time or impulse or momentum units [12].

$$
\iiint \int \rho\left(\frac{\partial u}{\partial t}+u \frac{\partial u}{\partial x}+v \frac{\partial u}{\partial y}+w \frac{\partial u}{\partial z}\right) \mathrm{dxdydz}=\iiint \int\left[\rho g_{x}-\frac{\partial P}{\partial x}+\mu\left(\frac{\partial^{2} u}{\partial x^{2}}+\frac{\partial^{2} u}{\partial y^{2}}+\frac{\partial^{2} u}{\partial z^{2}}\right)\right] \mathrm{dxdyd} z
$$

$\mathrm{N} \mathrm{sec}=$ units of impulse (momentum)

\section{Conservation of mass}

Let's divide each one of the three equations into units of force by the acceleration of gravity. The result will be in $\mathrm{Kg}$ or mass units.

$$
\frac{\iiint \rho\left(\frac{\partial u}{\partial t}+u \frac{\partial u}{\partial x}+v \frac{\partial u}{\partial y}+w \frac{\partial u}{\partial z}\right) \mathrm{dxdydz}}{g}=\frac{\iiint\left[\rho g_{x}-\frac{\partial P}{\partial x}+\mu\left(\frac{\partial^{2} u}{\partial x^{2}}+\frac{\partial^{2} u}{\partial y^{2}}+\frac{\partial^{2} u}{\partial z^{2}}\right)\right] \mathrm{dxdydz}}{g}=\frac{N}{\left(\frac{m}{\mathrm{sec}^{2}}\right)}=K g
$$

=units of mass

$$
\frac{\iiint p\left(\frac{d v}{d t}+u \frac{d v}{d x}+v \frac{d v}{d y}+w \frac{d v}{d z}\right) \mathrm{dxdydz}}{g}=\frac{\iiint\left[p g_{y}-\frac{d P}{d y}+\mu\left(\frac{d^{2} v}{d x^{2}}+\frac{d^{2} v}{d y^{2}}+\frac{d^{2} v}{d z^{2}}\right)\right] \mathrm{dxdydz}}{g}
$$

$=$ mass

$$
\frac{\iiint \rho\left(\frac{\partial w}{\partial t}+u \frac{\partial w}{\partial x}+v \frac{\partial w}{\partial y}+w \frac{\partial w}{\partial z}\right) \mathrm{dxdydz}}{g}=\frac{\iiint\left[\rho g_{z}-\frac{\partial P}{\partial z}+\mu\left(\frac{\partial^{2} w}{\partial x^{2}}+\frac{\partial^{2} w}{\partial y^{2}}+\frac{\partial^{2} w}{\partial z^{2}}\right)\right] \mathrm{dxdyd} z}{g}=\text { mass }
$$

$=$ mass

Now that the three equations are in mass units and, since the masses are the same, we can equate the three equations.

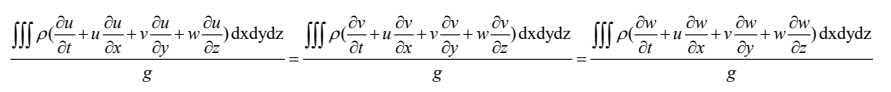

$\frac{\left.\iiint\left[\rho g_{x}-\frac{\partial P}{\partial x}+\mu \frac{\partial^{2} u}{\partial x^{2}}+\frac{\partial^{2} u}{\partial y^{2}}+\frac{\partial^{2} u}{\partial z^{2}}\right)\right] \mathrm{dxdydz}}{g}=\frac{\iiint\left[\rho g_{y}-\frac{\partial P}{\partial y}+\mu\left(\frac{\partial^{2} v}{\partial x^{2}}+\frac{\partial^{2} v}{\partial y^{2}}+\frac{\partial^{2} v}{\partial z^{2}}\right)\right] \mathrm{dxdydz}}{g}=\frac{\iiint\left[\rho g_{x}=\frac{\partial P}{\partial z}+\mu\left(\frac{\partial^{2} w}{\partial x^{2}}+\frac{\partial^{2} w}{\partial y^{2}}+\frac{\partial^{2} w}{\partial z^{2}}\right)\right] \mathrm{dxdydz}}{g}$

The equations of Navier Stokes, knowing the initial conditions, cannot predict the condition of the system. The system can be homogeneous, but it is not so at the molecular level, The initial conditions need to be determined statistically, either by Lagrangian or Eulerian views, which do not give us exhaustively the conditions of every infinitesimal volume that constitute it [12].

The unmeasured components constitute points of synergetic fluctuation that generate Lorenzian chaos, and so increasing unpredictability of the system [15].

Ideally, the system should be isolated, however, there is no such instance, thus the surroundings have incommensurable effects over the system, continuously changing its condition.

The system is perturbed by its measurement, there will always be uncertainty, at least, that of Heisenberg's [12].

As an Einsteinian argument, many concepts are part of science and to try to keep them simple is despised since they cannot be explained simpler than what is possible, such is the case of the Navier-Stokes equations.

Homeostatic mechanisms have the property of hysteresis [13], evidenced by the overcompensation with which they respond to disturbance.

Blood constitutes an anisotropic medium. In terms of a vector field, in the regions of the alveoli, it acts as a source of $\mathrm{O}_{2}$ and as a sink of $\mathrm{CO}_{2}$, while in regions corresponding to mitochondria, blood acts as a source of carbon dioxide and as a sink for molecular oxygen. Thus, maintaining a continuous generation of a gradient for both gases that, per se, determine the flow direction in terms of Fick's laws and Starling's Law. This effect is several orders of magnitude more accentuated due to the convection that is constituted by the bulk movement generated by the heart pump inside the body and the bulk movement of the gases in the respiratory tract [17].

Paradoxically, life depends on the increase of entropy consuming molecular oxygen and producing carbon dioxide in the mitochondria [17]. Also depending on the chaos produced by the action potential of the membranes, positive feedback, and in the generation of turbulence, in both fluid, gases on the one hand side and, liquid on the other, obeying the Navier-Stokes equations [13].

Isomorphically happens with nutrients, which in terms of the luminal membrane of intestinal epithelia, constitute sources towards the light of the vessels and sinks from the topological perspective of the enteral lumen. While the cellular regions of the vectorial field constitute sinks; at the same time, every one of the same cells constitutes a source of waste products. This obeys the Ficks laws and convection of the blood and gastrointestinal contents producing turbulence and chaos, obeying the Navier-Stokes equations and the Lorenzian chaos [13].

Thus, life depends on the thermodynamic advantage, which creates anabolism, which in turn, makes order from chaos without violating the second law of thermodynamics. This happens since the order created is done at the expense of energy obtained from the surrounding (nutrients) and molecular oxygen creating combustion and freeing energy from the exterior sources. The addition of these effects is always entropy; so the system diminishes its entropy at the expenses of over increasing the entropy in the surroundings. This proceeds in such a way that the overall entropy of the system plus the surrounding increases their entropy [18].

So, all the energy that we use comes from the harvesting of sunlight made by the chloroplast in the plants. The process is done cybernetically, without design, due to information. It obeys the mathematical theory of communication of Shannon, which is defined as the negative base 2 logarithm of the available states [19].

By the same token, the vector field corresponding to waste products has mainly nephrons as a sink. 


\section{Ergodic disquisitions}

Ergodicity models a point in a system, which could be a dynamical system or a stochastic process that will essentially visit all sub volumes of the space that the system moves in uniform and stochastically. Thus, the average behavior of the system can be strongly inferred from the trajectory of an indiscernible typical point. In a sufficiently large stochastic sample from a process, it corresponds to the average statistical properties of the whole process. Therefore, ergodicity corresponds to a special property of a system; it constitutes an absolute restriction statement such that is impossible for the whole system to be simplified, reduced partitioned, or factored into smaller components [15].

\section{Diffusive Disquisitions}

Fick's law of diffusion

$$
J=-D \frac{d \varphi}{d x}
$$$$
\text { Diffusionflux }=-\operatorname{diffisivity~}\left(\frac{d(\text { concentration })}{d(\text { position })}\right)
$$$$
\mathrm{D}=\frac{\text { area }}{\text { time }}=\frac{m^{2}}{\mathrm{sec}}
$$$$
\varphi=\text { concentration }=\left(\frac{\text { amount of substance }}{\frac{\text { volume }}{\text { distance }}}\right)=\frac{\text { amount of substance }}{(\text { distance })(\text { volume })}
$$$$
J=\frac{m^{2}}{\sec } \frac{\text { mole }}{(m)\left(m^{3}\right)}=\frac{\text { mole }}{(\mathrm{sec})\left(m^{2}\right)}=\frac{\text { mole }}{\text { time }(\text { area })}
$$$$
\mathrm{J} \text { in } R^{3}=-D \nabla \varphi=-D\left[\begin{array}{l}
\frac{\partial \varphi}{\partial x} \\
\frac{\partial \varphi}{\frac{\partial y}{\partial \varphi}} \\
\frac{\partial z}{\partial z}
\end{array}\right]=-D\left(\frac{\partial \varphi}{\partial x} i+\frac{\partial \varphi}{\partial x} j+\frac{\partial \varphi}{\partial x} k\right)
$$

$\dot{V}=\frac{\left(P_{1-} P_{2}\right) A x D}{T}=\frac{\nabla P x A x D}{T}=\frac{(\text { change in pressure) }(\text { Area })(\text { Diffusion constant })}{\text { Thikness }}$

$$
\begin{aligned}
& \frac{\text { Pressure }}{\text { Henry's constant }}=\text { concentration } \\
& D=\frac{\text { Solubility }}{\text { Molecular weight }}=\frac{\text { Solubility } \rightarrow \text { Henry's law }}{\sqrt{\mu W \rightarrow \text { Graham's law }}}
\end{aligned}
$$

\section{Logical disquisitions (doxastic and desiderative)}

The decisional logic has two matrix components: the doxastic logic and the desiderative logic. Doxastic and apophantic logic. Apodictic logic constitutes a mandatory inference, in doxastic logic, once the axioms are tentatively accepted (doxastically) true [20,21].

Desiderative logic: The estimation of the risk constitutes a belief (doxastic logic) vs. benefits (desiderative logic). This constitutes the logic of the decision. The practice of medicine should not be an instance in Nash equilibrium, conciliating false beliefs (doxastic logic) and unreachable desires (desiderative logic) [17].

\section{Bayesian disquisitions}

Hypertension was first described as a variation of a physiological characteristic that even though it was statistically within normal distribution, increased the risk of morbidity and mortality, therefore is considered a "risk-based disease", and the Bayesian approach may drive equivocal assumptions, especially if physiopathological components are not fully understood [17]. On the other hand, the Bayes theorem is pervasive in all experimental science. It has been a historical tragedy in terms of criminal law, but especially in science in what we have called the bayesian tragedy [22]. Formally:

Delta $(\Delta)$ is a probability space, where we can define a sigma-algebra of events, with a probability measure. Delta would be composed of all the events of $A$, that is, it is a partition of the sample space that is formed by all the people with symptoms, and " $\mathrm{D}=$ =" is an event that is intersecting the events of delta, therefore we can calculate conditional probabilities and apply Bayes' theorem $[23,24]$.

If $\Delta=\left\{\mathrm{D}_{\mathrm{e}}: \mathrm{e} \mathrm{J}\right\}$ is any class of mutually exclusive countable events,

$\mathrm{D}_{\mathrm{e}}=$ Disease

$\mathrm{A}=$ Abnormal result in the test

$\mathrm{D}_{\mathrm{j}}=$ No disease

$\mathrm{P}()=$ Bayesian Probability Function

If $\mathrm{A}$ is any abnormal test result with positive such that then:

$$
P\left(\left(\frac{D_{e}}{A}\right)\right)=\frac{P\left(\left(\frac{A}{D_{e}}\right)\right) \mathrm{P}\left(D_{e}\right)}{P(A)}=\frac{P\left(\left(\frac{A}{D_{e}}\right)\right) \mathrm{P}\left(D_{e}\right)}{\sum_{j e J} P\left(\left(\frac{A}{D_{j}}\right)\right) \mathrm{P}\left(D_{j}\right)}
$$

Catastrophic and Chaotic Disquisitions. Thom's Mathematical Theory of Catastrophes. Lorenz's Mathematical Chaos Theory.

The mathematical theory of catastrophes is a branch of mathematics that resulted from the discovery of abrupt changes as demonstrated by René Thom. For this reason, Thom was awarded the Fields Medal, the highest prize in the field of mathematics in the World [25].

Catastrophe constitutes the paroxysmal transition from two different states of affairs, so it has a Boolean behavior, one could say Manichaean. Catastrophe occurs with the decay of metastable energy, while chaos behaves in a continuous exponential or logistic growth. The energy for chaos propagation, as in the dominos reaction, is available from the potential energy possessed by every new element captured by the chaotic phenomenon [15].

Instructive types of catastrophic phenomena are: lighting, alpha, beta, and gamma nuclear decay, phosphorescence, the release of oxygen from hemoglobin, death is a catastrophic event, the entrance to sleep, ovulation, the latch lock, the all or nothing law of synaptic transmission, the boiling of water, the explosion of soap bubbles, balloons, balls, and tires, camels' backs broken when overridden, the emission of photons and electrons, the laughter, the Kuhnian reconfiguration, sensory identification: hearing, sight, smell and taste, popcorn, breaking a potato chip in the mouth, dripping, Buridan's ass decision, the decisional process, the steps of a Turing machine, hiccups, the sneeze, the production of a thymine dimer, the bifurcation of the vessels, the equation: $y=a /(x-b)$, the glacier detachment, the breaking of the glass, etc [25].

In both, chaos and catastrophe, energy is the potential energy of the elements that participate in the phenomenon [25]. Chaos 
vs. catastrophe: eureka phenomenon. Synaptic transduction is a catastrophe from a chaotic process.

The rupture of the artery in a hemorrhagic stroke is a catastrophic event.

There are catastrophic events that are preceded by a chaotic process.

The yawn extends to a catastrophic event. Keyboards are catastrophic and every key is a Zeeman Catastrophe Machine. The Cobordism is a catastrophe [25].

Lorenz's Chaos vs. Thom's Catastrophes. Chaos is exponential, while catastrophe is hyperbolic corresponding to $y=a /(x-b)$ when " $x$ " takes the value of " $b$ " [15].

\section{Disquisitions over turbulent flow [15]}

Reynold number is dimensionless

$$
\begin{aligned}
& \operatorname{Re}=\frac{\mathrm{u} \mathrm{L}}{v} \\
& \mathrm{u}=\text { flow velocity in } \frac{m}{\mathrm{sec}} \\
& \mathrm{v}=\text { kinematic viscosity in } \frac{m^{2}}{\mathrm{sec}} \\
& \operatorname{Re}=\frac{\left(\frac{m}{\mathrm{sec}} m\right)}{\frac{m^{2}}{\mathrm{sec}}}=\frac{\frac{m^{2}}{\mathrm{sec}}}{\frac{m^{2}}{\mathrm{sec}}}=1 \\
& \frac{\left(\frac{m}{\sec }\right)(m)\left(\frac{K g}{m^{3}}\right)}{\text { Pascal sec }}=\frac{\left(\frac{m}{m^{3}}\right)\left(\frac{K g m}{\sec }\right)\left(\frac{1}{\sec }\right)}{\text { Pascal sec }\left(\frac{1}{\sec }\right)}=\frac{\left(\frac{N m}{m^{3}}\right)}{\text { Pascal }}=\frac{\left(\frac{N}{m^{2}}\right)}{\text { Pascal }}=\frac{\left(\frac{N}{m^{2}}\right)}{\left(\frac{N}{m^{2}}\right)}=1
\end{aligned}
$$

$$
\begin{aligned}
& \operatorname{Re}=\frac{u L \rho}{\mu} \\
& \operatorname{Re}=\frac{u d \rho}{\mu}=\frac{u(2 r) \rho}{\mu} \\
& \frac{\left(0.03 \frac{\mathrm{cm}}{\mathrm{sec}}\right) 2\left(3 \times 10^{-6} \mathrm{~m}\right)\left(1,060 \frac{\mathrm{Kg}}{\mathrm{m}^{3}}\right)}{3 \times 10^{-3} \text { Pascal sec }}
\end{aligned}
$$$$
\frac{\left(0.03 \frac{\mathrm{cm}}{\mathrm{sec}}\right)\left(10 \frac{\mathrm{mm}}{\mathrm{cm}}\right)\left(6 \times 10^{-6}\right)\left(1,060 \frac{\mathrm{Kg}}{\mathrm{m}^{2}}\right)}{3 \times 10^{-3} \text { Pascal sec }}
$$$$
\frac{\left.(0.03)\left(6 \times 10^{-5}\right)(1,060) \frac{\mathrm{mmKg}}{\mathrm{sec} \mathrm{m}^{2}}\right)}{3 \times 10^{-3} \text { Pascal sec }}
$$$$
\frac{\left.\left(3 \times 10^{-2}\right)\left(6 \times 10^{-5}\right)\left(10^{3}\right) \frac{\mathrm{mmKg}}{\mathrm{sec} \mathrm{m}}\right)}{3 \times 10^{-3} \mathrm{Pascalsec}}
$$

$$
\frac{\left.\left(10^{-2}\right)\left(6 \times 10^{-5}\right)\left(10^{3}\right) \frac{\mathrm{mmKg}}{\sec \mathrm{m}^{2}}\right)}{10^{-3} \frac{N}{\mathrm{~m}^{2}} \sec }
$$

$$
\frac{\left(10^{-1}\right) \frac{m m K g}{\sec }\left(\frac{m}{10^{3} m m}\right)}{\frac{\operatorname{Kg}\left(\frac{m}{\sec ^{2}}\right)}{m^{2}} \sec m^{2}}
$$

$$
\operatorname{Re}=10^{-4}
$$

Turbulent flow is defined as having a Reynold number greater than 200. $10^{-4}$ is much less than 200 , therefore there is no turbulent flow in the capillaries.

\section{Disquisitions on the kolmogorov microscales of turbulent flow}

Kolmogorov microscales are the smallest scales in situations of turbulent flow. At the Kolmogorov scale, viscosity dominates, and the turbulent kinetic energy is dissipated into heat [15].

$\varepsilon$ (epsilon) is the average rate of dissipation, turbulence kinetic energy per unit of mass, with dimensions of energy/(time $\times$ mass), while $v(\mathrm{nu})$ corresponds to the kinematic viscosity of the fluid with dimensions of viscosity/density.

Kolmogorov conceived the concept that the smallest scales of turbulence are universal and that depend exclusively on $\varepsilon$ (epsilon) and $v(\mathrm{nu})$, for length scales from kilometers to less than a millimeter [15].

To comprehend the derivation of Kolmogorov microscales, it is required their dimensional analysis and, to inspire the reader, is done here as follows:

$v=$ Kinematic viscosity $=\frac{\text { Pascal } \mathrm{sec}}{\left(\frac{K g}{m^{3}}\right)}=\frac{\left(\frac{N}{m^{2}} \mathrm{sec}\right)}{\left(\frac{K g}{m^{3}}\right)}=\frac{\left(\frac{\left(K g \frac{m}{\mathrm{sec}^{2}}\right)}{m^{2}} \sec \right)}{\left(\frac{K g}{m^{3}}\right)}=\frac{m^{2}}{\mathrm{sec}}$ $\varepsilon=$ energy dissipation rate per unit mass

$\varepsilon=\frac{\left(\frac{\text { Energy }}{\text { time }}\right)}{\text { mass }}=\left(\frac{\text { Power }}{\text { mass }}\right)=\left(\frac{\text { Watt }}{K g}\right)=\frac{\left(\frac{\text { Joule }}{\mathrm{sec}}\right)}{K g}=\frac{\left(\frac{N m}{k g}\right)}{\sec }=\frac{\left(\frac{\left(K g \frac{m}{\sec ^{2}}\right)}{K g}\right)}{\sec }=\frac{m^{2}}{\sec ^{3}}$

Kolmogorov Length Scale $=\eta=\left(\frac{v^{3}}{\epsilon}\right)^{\frac{1}{4}}=\left(\frac{\left(\frac{m^{2}}{\mathrm{sec}}\right)^{3}}{\frac{m^{2}}{\sec ^{3}}}\right)^{\frac{1}{4}}=\left(\frac{\frac{m^{6}}{\sec ^{3}}}{\frac{m^{2}}{\sec ^{3}}}\right)^{\frac{1}{4}}=\left(m^{4}\right)^{\frac{1}{4}}=m$ $3 \times 10^{-3}$ Pascal sec 
Kolmogorov Time Scale $=T_{\eta}=\left(\frac{v^{3}}{\epsilon}\right)^{\frac{1}{2}}=\left(\frac{\left(\frac{m^{2}}{\mathrm{sec}}\right)}{\frac{m^{2}}{\sec ^{3}}}\right)^{\frac{1}{2}}=\left(\sec ^{2}\right)^{\frac{1}{2}}=\sec$

Kolmogorov Velocity Scale $=u_{\eta}=(\in v)^{\frac{1}{4}}\left(\left(\frac{m^{2}}{\mathrm{sec}^{3}}\right)\left(\frac{m^{2}}{\mathrm{sec}}\right)\right)^{\frac{1}{4}}=\left(\frac{m^{4}}{\mathrm{sec}^{4}}\right)^{\frac{1}{4}}=\frac{m}{\mathrm{sec}}$

Role of Endothelium in Blood Pressure Regulation Through NO and Endothelial Vasoconstrictive Factors on the Kolmogorov's Microscales of Turbulent Flow.

It is always important to remember that, as its name implies, angiotensin controls tension (Laplace tension) rather than transmural pressure. It is not called "angiopressin".

In the cells of the vascular smooth muscle, Angiotensinogen II binds to a $\mathrm{G}$ protein which is coupled to AT1A receptors, thus activating phospholipase $\mathrm{C}$, raising $\left[\mathrm{Ca}^{2+}\right] \mathrm{i}$, and producing vasoconstriction. Reduced perfusion in the kidney causes the release of renin. Plasma angiotensinogen II levels elevate, leading to strong vasoconstriction, both in the splanchnic and renal circulations [10]. This reduced renal blood flow produces even more renin release and higher ANG II levels, a dangerous Lorenzian chaotic positive-feedback phenomenon that can generate acute renal failure.

Endothelial Cells Produce Endothelins (ETs) that bind to ETA receptors on Vascular Smooth Muscle Cells (VSMCs), thus causing vasoconstriction. Molarly ETs are the most powerful vasoconstrictors [10].

The enzyme kininase II is the same enzyme as ACE. Thus, the very same enzyme (ACE) that generates a vasoconstrictor (ANG II) also inactivates vasodilators (bradykinin). The bradykinin binds to the $\mathrm{B}_{2}$ receptors on the membrane of endothelial cells, producing the release of NO and of prostaglandins and thus vasodilation. Similar to histamine, the kinins produce vasodilation but contract visceral smooth muscle [10].

Many types of cells synthesize prostaglandins, which are derivatives of arachidonic acid. Prostacyclin causes strong vasodilation. PGE also causes vasodilation. The Prostaglandins in the kidney, endothelial cells, vascular smooth muscle cells, mesangial cells, and interstitial and tubule cells of the renal medulla are especially important for producing locally acting prostaglandins from the arachidonic acid through the cyclooxygenase [10].

The renal endothelial cells through Nitric Oxide Synthase (NOS) produce nitric oxide from L-arginine. Nitric oxide has a profound smooth muscle relaxing effect and produces significant renal vasodilation. Injected NOS inhibitors into the circulation constrict afferent and efferent arterioles, thus increasing renal vascular resistance and generate an important fall of RBF and GFR. In the endothelial cells, the enzyme nitric oxide synthase generates nitric oxide from arginine. Nitric oxide then activates another enzyme, guanylyl cyclase which is in a soluble form in the vascular smooth muscle cells, thus causing vasodilation. Nitric oxide is a strong vasodilator, it has not a significant homeostatic role in overall blood pressure; however, the role of nitric oxide is paramount in the control of local perfusion which is what matters [10].

Nitric oxide is a very reactive, free radical which is short-lived. Nitric oxide is a dissolved gas produced from a family of enzymes called (NOS) enzymes. The activation of these enzymes (NOS) starts when an extracellular agonist as acetylcholine binds to a receptor in the plasma membrane, triggering the incoming of the divalent cation $\mathrm{Ca}^{2+}$, which binds to CaM in the cytoplasm stimulating NOS. In smooth muscle, Nitric oxide stimulates the sGC, which thus converts GTP to cGMP, by activating PKG, leading to relaxation of smooth muscle [10].

Pressure should be defined as transmural pressure, axial pressure and Laplacian tension. All the considerations must be adapted to Bayesian risk.

The environment in the surroundings corresponds to conditions of turbulence that behave according to kolmogorov microscales of velocity, time, and distance as derived in this paper. Furthermore, the molecular behavior obeys the Ficks law of diffusion as derived above in this paper.

Disquisitions Over Poiseuille Law: Is Decay of the Flux a Function of the Fourth Power of the Radius?

$$
\begin{gathered}
\Delta P=\dot{V} R \\
\Delta P=\dot{V} \frac{8 n L}{\pi r^{4}} \\
\Delta P=v \pi r^{2} \frac{8 n L}{\pi r^{4}} \\
\Delta P=\frac{8 v n L}{r^{2}} \\
\dot{V}=\Delta P \frac{\pi r^{4}}{8 n L} \\
\dot{V}=\frac{F}{A} \frac{\pi^{2} r^{4}}{8 \pi n L} \\
\dot{V}=\frac{F}{A} \frac{A^{2}}{8 \pi n L} \\
\dot{V}=F \frac{A}{8 \pi n L} \\
\dot{V}=F \frac{\pi r^{2}}{8 \pi n L} \\
\dot{V}=F \frac{r^{2}}{8 n L} \\
r^{2}=\frac{8 \dot{V} n L}{F}=\frac{8 v n L}{\Delta P}
\end{gathered}
$$




$$
\begin{gathered}
\frac{v}{\left(\frac{W}{V}\right)}=\frac{\left(\frac{v}{t}\right)}{\Delta P} \\
v=\frac{\left(\frac{v}{t}\right)\left(\frac{W}{V}\right)}{F} \\
v=\frac{W}{F t} \\
v=\frac{F d}{F t} \\
v=\frac{d}{t} \\
v \equiv v
\end{gathered}
$$

We have derived from Poiseuille's equation the following:

$$
\dot{V}=F \frac{r^{2}}{8 n L}
$$

Therefore, if the radius remains unchanged, the flux depends linearly on the force and is inversely proportional to the length of the vessel and to the viscosity.

We must distinguish between descriptive equations and representative equations. Newton's, Poiseuille's, Bernoulli's, NavierStokes, and Eistein's equations are descriptive and correspond to laws of the Universe, which means apodictic, while Kermack-McKendrick are modeling equations but not correspond to laws of the Universe.

\section{Disquisitions over the first law of thermodynamics, einstein- ian conservation of total energy}

The true Einsteinian Total energy equation.

$$
\begin{aligned}
& E=m c^{2} \\
& \rho=m v \\
& E^{2}=m^{2} c^{4}+\rho^{2} v^{2}
\end{aligned}
$$

Dimensional analysis:

$$
J^{2}=\left(K g \frac{m}{\mathrm{sec}}\right)^{2}\left(\frac{m}{\mathrm{sec}}\right)^{2}+K g^{2}\left(\frac{m^{4}}{\sec ^{4}}\right)
$$

Disquisitions over mass conservation [13]. Lavoisier conservation of the mass. Fallacy over decreased venous return. Diminished preload volume would be a violation of the mathematical theory of queues [26] and of the first law of thermodynamics too.

During systole, which begins when the atrioventricular valves close, ventricular pressure increases to the point at which semilunar valves open. Continuing in systole, now being left ventricle and aorta one topological space, pressure increases until it reaches the maximum point, $120 \mathrm{mmHg}$ (called the systolic blood pressure), and then begins to decrease as the left ventricle is relaxing (left ventricular pressure is less than the aortic pressure, allowing for little blood to return to the left ventricle before the aortic valve closes). Because the only terminal output from the aorta is the capillaries, blood goes from the aorta eventually to the capillaries, decreasing diastolic aortic pressure. When the ventricular pressure is above the diastolic blood pressure of the aorta, the aortic valves open again, increasing the aortic pressure now in systole, so the instant at which the aortic valve opens is when the aorta has the smallest diastolic blood pressure and it is called the diastolic blood pressure. What determines the value of the diastolic blood pressure is the ventricular contraction and how quickly blood flows from the aorta to the capillaries. The Pressure obtained with the sphygmomanometer corresponds to the maximum transmural pressure in systole and the minimum transmural pressure in diastole. If the left ventricle contracts exactly after the systole, when the left ventricle has reached a greater pressure than the aorta, the aortic valve will open and so the diastolic blood pressure will be very close to the systolic blood pressure. So, we can see that tachycardia increases diastolic blood pressure and bradycardia decreases diastolic pressure [8].

If the pumping action of the heart stops, the blood will continue moving inertially, hysteretically [25], for a few seconds, in the same direction in all the cardiovascular system, until the energy gradient disappears reaching equilibrium, thus, the axial pressure would be zero. In this point, the axial meta-topology would be the transition of the whole system in just one communicated space and, in an apparent paradox, the transmural pressure would be approximately $7 \mathrm{mmHg}$, because the cardiovascular system has been inflated to $7 \mathrm{mmHg}$ since it still contains blood expanding the vessels, even though it is not being pumped by the heart. This is called the mean systemic filling pressure [8].

When the left ventricle contracts the aortic pressure increases because arteries are elastic and so there is a storage of elastic potential energy in the walls before blood flows from the aorta, and eventually to the capillaries as the arterial walls lose elastic potential energy [8].

Extending the lapidary expression by George L. Brengelmann: Perhaps in many situations, physicians have made correct interventions based on the idea that mean systemic pressure drives venous return [27]. However, reaching the right answer for the wrong reason constitutes a mixture of intuition with luck. It would be much better to move ahead empower them with knowledge and understanding of how blood volume results apportioned among vascular in the topological spaces of the cardiovascular system due to their energetic gradients.

\section{Disquisitions over laplace's tension versus transmural pres- sure}

For over 80 years, transmural pressure measurement has been the hallmark of hypertension diagnosis, although many sources of errors have been described, most of the efforts to improve this measurement have not been effective in terms of neither diagnosis, nor followup $[28,29]$. Notwithstanding, the function to optimize is perfusion through the axial gradient of energy density. In clinical and surgical settings, transmural pressure is the gradient between an arbitrary point in the vessel (brachial artery) and the atmospheric pressure. Thus, the wall is constituted not only by the wall of the artery but also by all surrounding tissue, including muscle, aponeurosis, subcutaneous fat, and skin. The sphygmomanometer has to overcome the thick skin before having any pressure effect against the artery. The decrease in body weight and consequently the decrease in the brachial tissue volume decrease the periarterial tissue pressure giving a false reading of hypertension. 


\section{Laplacian Tension Rather Than Transmural Pressure, Capil- laries Vs. Vena Cava [8]}

If we compare two vessels, of extreme distinct radius, they show a discrepancy between wall tension and pressure. A large vessel, like the vena cava, tolerates only $10 \mathrm{~mm} \mathrm{Hg}$ of transmural pressure; however, it possesses a large mass of elastic tissue. Alternatively, a capillary, which tolerates a transmural pressure of 20 to $30 \mathrm{~mm} \mathrm{Hg}$, does not contain elastic tissue. What the vessels resist is wall tension, rather than transmural pressure. Laplace's law establishes that wall tension is the result of multiply transmural pressure by the radius. Thus, the wall tension in a capillary $(10$ dynes $/ \mathrm{cm})$ is drastically smaller than that in the vena cava $(18,000$ dynes $/ \mathrm{cm})$, even though the capillary is at a much higher pressure [30].

A phenomenological different scenery occurs at the level of capillaries in which the realm of the transversal meta-topology operates: Diffusion of liposoluble gases, diffusion of hydrosoluble substances, convection of water producing filtration and reabsorption. At this capillary level, the pressure gradient operates through the capillary wall i.e., between the intracapillary lumen and the interstitial space; even more specifically, between the side facing the luminal face of the capillary and the abluminal face of the endothelial cell which correspond to the subglycocalyx space [8].

\section{Laplacian Disquisitions}

It is the Laplacian tension rather than transmural pressure that should attract attention in the surgical and clinical settings to avoid tragical atrocity.

Laplace law

$$
F=k \Delta L
$$

Units of $\mathrm{k}$ are:

$$
\begin{aligned}
& K g \frac{m}{\sec ^{2}}=k(m) \\
& k=\frac{K g}{\sec ^{2}}
\end{aligned}
$$

Wall tension:

Dividing by length

$$
\begin{aligned}
T & =\frac{\left(\frac{K g}{\sec ^{2}}\right) m}{m}=\frac{\left(\frac{K g}{\sec ^{2}}\right) m}{m}\left(\frac{m}{m}\right)=\frac{N}{m^{2}} m=\frac{N}{m} \\
T & =\Delta P r \\
T & =\frac{N}{m^{2}} m=\frac{\text { Work }}{\text { Area }} \\
T & =\Delta \mathrm{P} \mathrm{r} \\
T & =\frac{F}{A} r \\
T & =\frac{F}{\pi r^{2}} r \\
T & =\frac{F}{\pi r}
\end{aligned}
$$

$$
\begin{aligned}
& T=\frac{N}{m} \\
& T=\frac{\left(K g \frac{m}{\sec ^{2}}\right)}{m} \\
& T=\frac{K g}{\sec ^{2}}
\end{aligned}
$$

\section{Bernoullian Disquisitions}

To cogitatively grasp the transcendence of the elements of the Bernoulli's equation we have to appreciate them in terms of power and momentum [10]. If the fluid is static, the velocities are equal to zero:

$$
\begin{aligned}
& P_{1}+\frac{1}{2} \rho v_{1}^{2}+\rho g h_{1}=P_{2}+\frac{1}{2} \rho v_{2}^{2}+\rho g h_{2} \\
& P_{1}+\rho g h_{1}=P_{2}+\rho g h_{2} \\
& P_{1}-P_{2}=\rho g\left(h_{2}-h_{1}\right)
\end{aligned}
$$

Bernoulli's equation in terms of power

$$
\begin{aligned}
& P_{1}+\frac{1}{2} \rho v_{1}^{2}+\rho g h_{1}=P_{2}+\frac{1}{2} \rho v_{2}^{2}+\rho g h_{2} \\
& P_{1} \dot{V}+\frac{1}{2} \rho v_{1}^{2} \dot{V}+\rho g h_{1} \dot{V}=P_{2}+\frac{1}{2} \rho v_{2}^{2} \dot{V}+\rho g h_{2} \dot{V} \\
& \frac{N}{m^{2}}\left(\frac{m^{2}}{\mathrm{sec}}\right)+\left(\frac{K g}{m^{3}}\right)\left(\frac{m^{2}}{\mathrm{sec}^{2}}\right)\left(\frac{m^{3}}{\mathrm{sec}}\right)+\left(\frac{K g}{m^{3}}\right)\left(\frac{m}{\mathrm{sec}^{2}}\right) m\left(\frac{m^{3}}{\mathrm{sec}}\right) \\
& \frac{N m}{\mathrm{sec}}+\frac{K g m^{2}}{\sec ^{2}}\left(\frac{1}{\mathrm{sec}}\right)+\frac{K g m^{2}}{\mathrm{sec}^{2}}\left(\frac{1}{\mathrm{sec}}\right) \\
& \frac{J}{\mathrm{sec}}+\frac{J}{\mathrm{sec}}+\frac{J}{\mathrm{sec}}=w a t t
\end{aligned}
$$

Bernoulli's equation in terms of momentum

$$
\begin{aligned}
& P_{1} \Delta t+\frac{1}{2} \rho v_{1}^{2} \Delta t+\rho g h_{1} \Delta t=P_{2} \Delta t+\frac{1}{2} \rho v_{2}^{2} \Delta t+\rho g h_{2} \Delta t \\
& \frac{N}{m^{2}} \sec +\left(\frac{K g}{m^{3}}\right)\left(\frac{m^{2}}{\sec ^{2}}\right) \operatorname{seg}+\left(\frac{K g}{m^{3}}\right)\left(\frac{m}{\sec ^{2}}\right) m \mathrm{sec} \\
& K g\left(\frac{m}{\sec ^{2}}\right) \frac{\sec }{m^{2}}+\left(\frac{K g}{m^{2}}\right)\left(\frac{m}{\mathrm{sec}}\right)+\left(\frac{K g}{m^{2}}\right)\left(\frac{m}{\mathrm{sec}}\right) \\
& \frac{\rho}{m^{2}}+\frac{\rho}{m^{2}}+\frac{\rho}{m^{2}}=\frac{\rho}{A} \backslash
\end{aligned}
$$

The effective determinant of the blood flow obeys the Bernoulli's equation in terms of energy, rather than pressure [13].

The hemodynamic inertia of the blood and vessels makes the pressure diminish whenever the velocity of flow increases. 


\section{Derivative of momentum with respect to time:}

$$
\begin{aligned}
& F=\frac{d(m v)}{d t} \\
& N=\frac{K g\left(\frac{m}{\mathrm{sec}}\right)}{\sec } \\
& N=N
\end{aligned}
$$

Where $\mathrm{F}$ is force and $\mathrm{v}$ is its velocity $[31,32]$.

$$
F=m \frac{d v}{d t}=m a
$$

It is usual but wrongly accepted, that fluids flow from a higher to a lower pressure, which is inaccurate. Fluids flow from a higher to lower total energy. This energy is composed of pressure, which is potential energy and kinetic energy [10]. This is the basis of the Bernoulli 's effect. As blood flows along a horizontal vessel with a narrow middle region, which has half the diameter of the two extremes, the pressure in the middle segment is lower than the pressure at the end of the vessel. Paradoxically, the blood flows against the pressure gradient from the lower-pressure middle segment to the higher-pressure distal segment of the vessel.

Flow is the product of cross-sectional area times the velocity. Since the flow is equal in both segments of the tube, but the cross-sectional area in the middle is lower by a factor of 4 , then the velocity in the middle segment has to be 4 times higher. Even though the fluid in the middle segment has a lower potential energy (pressure $=60$ ) than the fluid at the distal extreme of the vessel (pressure $=80$ ), it has a 16-times higher kinetic energy. Therefore, the total energy of the blood in the middle exceeds that in the distal segment, so that the blood flows down the fluid energy (potential and kinetic) gradient [8] (Figure 1).

This is an instance of a reversible conversion between pressure, which is potential energy [10], and velocity which is kinetic energy, because velocity changes along the length of a vessel even though the blood flow is constant. These changes in velocity contribute to the changes in pressure inside the aorta (Figure 2).

\section{Bernoulli 's equation in terms of energy}

$$
\begin{aligned}
& P_{1}+\frac{1}{2} \rho v_{1}^{2}+\rho g h_{1}=P_{2}+\frac{1}{2} \rho v_{2}^{2}+\rho g h_{2} \\
& \frac{N}{m^{2}}+\left(\frac{K g}{m^{3}}\right)\left(\frac{m^{2}}{\mathrm{sec}^{2}}\right)+\left(\frac{K g}{m^{3}}\right)\left(\frac{m}{\mathrm{sec}^{2}}\right) m \\
& \frac{N}{m^{2}}\left(\frac{m}{m}\right)+\left(\frac{K E}{V o l}\right)+\left(\frac{P E}{V o l}\right)=\frac{E}{V o l}=\frac{\text { Joules }}{m^{3}}
\end{aligned}
$$

Since a low-pressure system has the potential to do work in the surrounding medium, then, it is evident that pressure is a measure of potential energy stored per volume. Pressure is therefore related to energy density and can be expressed in units such as Joules per cubic meter, which is mathematically equal to the Pascal unit.

Integration of Momentum whit Respect to Velocity is Kinetic Energy

$$
\begin{aligned}
& \rho=m v \\
& \int \rho d v=\int m v d v=\frac{1}{2} m v^{2}+C=K E
\end{aligned}
$$

$$
\begin{aligned}
& F=m g \\
& \frac{F}{A}=\frac{m g}{A}
\end{aligned}
$$

Given that

$$
m=\rho V o l
$$

Then:

$$
\begin{aligned}
& \frac{F}{A}=\frac{(\rho V o l) g}{A} \\
& P=\rho g h \\
& \text { Pascal }=\left(\frac{K g}{m^{3}}\right)\left(\frac{m}{\mathrm{sec}^{2}}\right) m \\
& \frac{N}{m^{2}}=\frac{K g}{m \mathrm{sec}} \\
& \frac{K g\left(\frac{m}{\mathrm{sec}^{2}}\right)}{m^{2}}=\frac{K g}{m \mathrm{sec}} \\
& \frac{F}{A}\left(\frac{d}{d}\right)=\frac{\text { Work }}{\text { Vol }}=\frac{\text { Joule }}{m^{3}}
\end{aligned}
$$

\section{Eulerian vs. lagrangian analytical approaches}

The Lagrangian approach to the study of flow as if the observer travels in a particle; an allegorical analogy would be traveling passively in the fluid. Alternatively, the eulerian approach to the study of flow consists of observing all the particles of the fluid that pass by an arbitrary fixed point in a transverse area in the trajectory of the fluid [13].

\section{Apophantic logos as apodictic conclusions}

Blood moves according to the energy gradient and not the pressure gradient increased entropy [8]. It is not the perfusion but the convection in the capillary; it is the equilibrium, paradoxically it is the entropy.

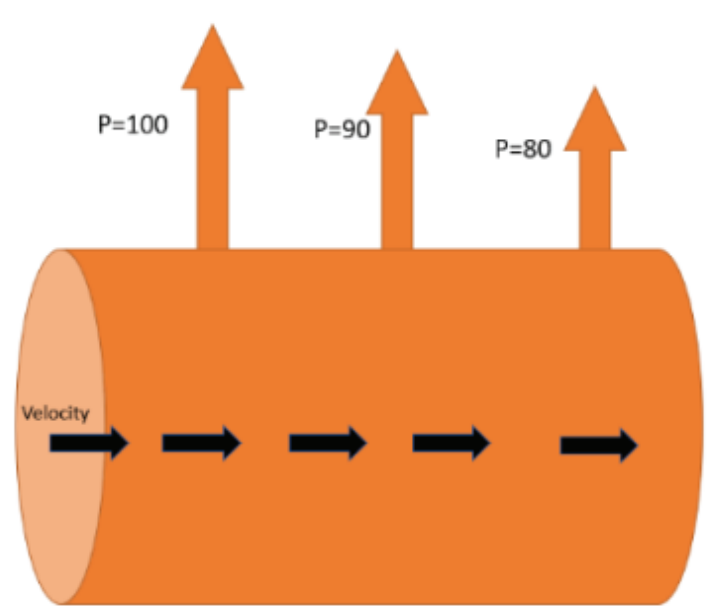

Figure 1: Fluids flow from a lower to higher pressure. 


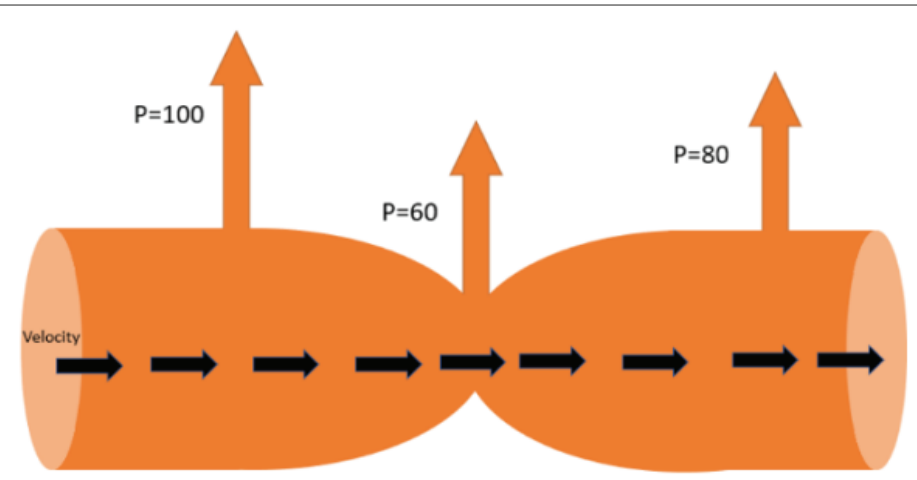

\begin{tabular}{|l|c|c|c|}
\hline Cross-sectional área (A) & 1 & $1 / 4$ & 1 \\
\hline Pressure (P) & 100 & 60 & 80 \\
\hline Velocity (V) & 2 & 8 & 2 \\
\hline Kinetic energy (KE) & 2 & 32 & 2 \\
\hline Total Energy (E) & 102 & 92 & 82 \\
\hline
\end{tabular}

Figure 2: Instance of a reversible conversion between pressures.

Disquisitions Over the Vascular Meta-topology. Axial Metatopology Vs. Transmural Meta-topology [32].

Axial meta-topology consists of the dynamic topological transformation of the cardiovascular system between systole and diastole. In the realm of mathematics, mainly in geometric topology, Milnor's surgery theory is a set of mathematical techniques to create one finite-dimensional manifold starting from another [33,34].

During systole, the cardiovascular system constitutes two communicated topological spaces: One topological continuous space consists of the left ventricle, aorta, systemic arteries, arterioles, capillaries, venules, cava veins, and right atrium. The other topological space consists of the right ventricle, pulmonary artery, pulmonary capillaries, and left atrium. During diastole the cardiovascular system constitutes two communicated topological spaces: one from the left ventricle, left atrium, pulmonary veins, pulmonary capillaries, pulmonary artery, the other consist in the right ventricle, right atrium, cava veins, systemic capillaries, systemic arteries, and the aorta [33].

There are two ephemeral transitions (the isovolumetric relaxation and isovolumetric contraction) in which there are four topological spaces in the cardiovascular system: one space is the left ventricle, other space is the right ventricle, other space is from the left atrium, pulmonary veins, pulmonary capillaries, pulmonary artery; and, the last space consists in the right atrium, cava veins, systemic capillaries, systemic arteries, and the aorta.

In the cardiac cycle, there are fourth Thom's catastrophic transitions: 1) closure of atrioventricular valves, 2) opening of semilunar valves, 3 ) closure of semilunar valves and 4) opening of atrioventricular valves.

Transmural Meta-topology Consists of Multiple Topological Spaces $[33,35]$.

The heterogeneity of the blood converts the same cardiovascular system into different topological entities, depending on the point of analysis from the elements of blood. Thus, the cardiovascular system is a diverse meta-topological structure depending on the point of view.
On a first approximation, we take the following points as frames of reference: Cellular (erythrocyte), protein molecules, monosaccharides (glucose), electrolytes, liposoluble gases, and water.

Solutes in the capillary move by transcapillary (transmural) diffusion, while the water moves by transcapillary convection (transmural).

\section{General Recommendations for Physicians and Medical Students}

There is a channel about math, science, and medicine with more than 7,000 lessons in video, among them; more than 100 are related to the cardiovascular system [36].

Follow the equations and derivations, starting with the Poiseuille's equation be aware of misconceptions that appear everywhere including in highly recognized medical texts, focus on perfusion rather than in transmural pressure. Be aware of transmitting the right concepts to patients, colleagues, residents, medical students, and medical personnel. It is an act of cruelty not to proceed in such a manner.

Since it is expected that the now informed physicians will receive objections based on doxastic logic and desiderative logic, we suggest they acquire the dexterity to express these concepts since the biophysical and mathematical fundamentals used here are natural laws. Any instance in which experimental results, clinical experience, policies, or protocol are opposed to the Navier-Stokes', Einstein's, Poiseuille's, and Bernoulli's equations would be a case of anti-scientific behavior.

We consider pertinent the reviewer's suggestion of extract the recommendation for physicians.

Do not accept the misleading entelechial expression of blood pressure anymore without questioning where it is transmural pressure, driving pressure, Laplacian tension. This last one requires by definition the transmural pressure in two different points of a vessel.

The transmural pressure is the gradient between the pressure in a point within the vessel and the atmospheric pressure, which is the 
one measured by the physician. It is the difference of the transmural pressure taken at two different points in a vessel. The Laplacian tension is the transmural pressure times the radius of the vessel.

Do not ever forget that the homeostat is the product of natural selection selecting the most successful genes in reproduction terms, which is its number of copies in the next generations. The homeostat do not select for health or survival except as part of reproductive success.

In doxastic logic the premises are beliefs and in desiderative logic the premises are wishes. The phenomenological reality of the universe is indifferent to beliefs and desires.

New Knowledge and Recommendations for the Physicians (Table 1).

This corresponds to the more transcendent concepts to the acquisition of new knowledge. As expressed by Bertrand Russell in Introduction to Mathematical Philosophy [37,38]. It must have required many ages to discover that a brace of pheasants and a couple of days were both instances of the number 2 [37].

There is not such a thing as diminishing the venous return. The venous return is exactly equal to the cardiac output. It is the principle of conservation of matter of Lavoisier, and also the first law of thermodynamics equivalent to the Einstein `s equation. One Hundred Authors against Einstein was published in 1931 [38]. Einstein replied that to defeat relativity one did not need the word of 100 scientists, just one scientific rebuttal.

In every mathematical transformation, we have given extreme openness to allow refutations, either formally (mathematical inconsistency) or through a crucial Popperian experiment [1]. We would stoically acknowledge it in any such instance, otherwise, we will conclude, in an Aristotelian and Laplacian's isomorphism...

...Res ipsa loquitur, ergo, quod erat demonstrandum.

Table 1: A summary of the new knowledge for the physicians (biophysical rather than anecdotal or dogmatic conceptions) and the recommendations of how to apply this knowledge, the atrocities that every physician should understand and thus avoid.

\begin{tabular}{|c|c|}
\hline 1 & $\begin{array}{l}\text { Verify in Poiseuille's equation derivation that Perfusion (flow) does not decay with the fourth power of the radius, but with the second } \\
\text { power of the radius. }\end{array}$ \\
\hline 2 & $\begin{array}{l}\text { When physicians see the occlusion of an artery, they should measure the radius rather than the cross-sectional area, alternatively if they } \\
\text { measure the cross-sectional area, they must note that the flux decays linearly as demonstrated in the derivation. }\end{array}$ \\
\hline 3 & $\begin{array}{l}\text { Be aware that by reducing the driving pressure with no vasodilators-antihypertensive drugs, we are decreasing axial pressure in the flow } \\
\text { and consequently the perfusion. }\end{array}$ \\
\hline 4 & $\begin{array}{l}\text { Realize that the sphygmomanometer measures transmural pressure and not driving pressure which is what produces perfusion clearly } \\
\text { described in Boron's Medical Physiology. }\end{array}$ \\
\hline 5 & Analyze with the equations why the main hemodynamic cause of damage is not transmural hypertension but Laplacian's tension. \\
\hline 6 & $\begin{array}{l}\text { Be knowledgeable that the damage to the arteries does not depend on transmural pressure but on the energy density per time, Joules } \\
\text { per cubic meter per second, or Watts per cubic meter. }\end{array}$ \\
\hline 7 & Observe that transmural hypertension, ceteris paribus increases perfusion. \\
\hline 8 & $\begin{array}{l}\text { Review that the baroreceptors do not respond to transmural pressure but Laplacian arterial tension, as described in Boron's Medical } \\
\text { Physiology. }\end{array}$ \\
\hline 9 & $\begin{array}{l}\text { Know that the brain and the heart have self-regulation of their perfusion, but vasodilators increase perfusion in other tissues, reducing } \\
\text { cerebral and coronary perfusion due to the stolen effect. }\end{array}$ \\
\hline 10 & $\begin{array}{l}\text { Appreciate that strictly, all gradients constitute potential energy, as happens in the instances of the concentration gradients, temperature } \\
\text { gradients, pressure gradients, and electrical gradients. }\end{array}$ \\
\hline 11 & $\begin{array}{l}\text { Observe that the derivative of pressure with respect to time, that is the change in pressure due to change in time, is the derivative of } \\
\text { the work per volume per time (change in work density due to time), that is, power density. }\end{array}$ \\
\hline 12 & Concentrate on the fact that what determines the perfusion is the axial gradient, not of pressure but of energy. \\
\hline 13 & Hyperbolically if we consider taking the pressure of a pachyderm, we would obtain readings significantly higher. \\
\hline 14 & Note that pressure is, in reality, energy density, which means, energy per infinitesimal unit of volume. \\
\hline 15 & $\begin{array}{l}\text { Never forget that the venous return consists of the blood flow returning to the right heart. Because the input of the right side must } \\
\text { equal its output, then in the steady-state situation, the cardiac outputs of the right and left sides are essentially equal. Consequently, the } \\
\text { systemic venous return matches the systemic cardiac output. The venous return should be equal to or less than the cardiac output. The } \\
\text { heart, as a pump, cannot expel a volume that has not been received; notwithstanding, in the case of valve regurgitation, the heart can } \\
\text { expel a fraction of the venous return twice. The clinical physician should ask himself or herself: Is the preload volume in the EDV or the } \\
\text { pressure at the time of the EDV which has been diminished before starting the isovolumic contraction? This corresponds to Einstein's } \\
\text { equation: the energy in the universe is conserved. }\end{array}$ \\
\hline 16 & $\begin{array}{l}\text { We must always keep in mind that the probability that a patient with a disease " } D \text { " has a finding " } F \text { " is totally different from the } \\
\text { probability that a patient that has the clinical finding " } F \text { " has disease " } D \text { ". This is the core of the Bayesian analysis. }\end{array}$ \\
\hline
\end{tabular}




\section{“Tabula Gratulatoria”}

We are deeply grateful to the widely recognized international expert in cardiovascular electrophysiology, Dr. Luis Molina. We consider a privilege his wise criticism and deep scientific analysis, as well as his pedagogical recommendations on the content of this work.

We are also in historical debt to the distinguished researcher and international authority in computational logic and mathematical modeling, Dr. Juan Frausto, for reviewing the mathematical content and consistency of the transformations of the differential equations, that lead us, apodictically, to demonstrate the atrocities that occur when biophysics is neglected, especially the Navier Stokes equations.

\section{References}

1. Popper KR (2002) The Logic of Scientific Discovery. Routledge, USA.

2. Ronald V (2019) Systemic Hypertension: Mechanism and Diagnosis. In: Mann DL, Zipes DP, Braunwald E, Tomaselli GF, Libby P, et al. (eds) Braunwald's Heart Disease. $11^{\text {th }}$ Edition, Elsevier, Canada.

3. Lamothe N, Lamothe M, Lamothe D, Lamothe PJ (2020) Application of the Parsimony Principle of Exponential Functions to the Production of COVID-19 Immunity, According to Bayesian Theorem and Cybernetics, to Tame Anti-scientific Doxastic Logic and the Pandemic. Int J Biol Med 2: 33-47.

4. Lamothe N, Lamothe M, Lamothe D, Sierra C, González-Téllez-Girón $\mathrm{CH}$, et al. (2021) Bayesian Model for COVID-19 to Achieve Immunity by Parsimony of Exponential Functions Minimizing the Inoculum. J Emerg Dis Virol 6: 1-11.

5. Lamothe $\mathrm{M}$, Lamothe $\mathrm{N}$, Lamothe $\mathrm{D}$, Hernández-Garcia $\mathrm{A}$, Castillo C, et al. (2021) Exponential Parsimony to Generate Herd Immunity Against SARS-CoV2 Cybernetically Restricting Doxastic and Desiderative Logics. International Journal of Coronaviruses 2: 11-22.

6. Sánchez-Hernández JP, Frausto-Solís J, González-Barbosa JJ, SotoMonterrubio DA, Maldonado-Nava FG, et al. (2021) A Peptides Prediction Methodology for Tertiary Structure Based on Simulated Annealing 26: 39.

7. Frausto-Solís J, Hernández-González LJ, González-Barbosa JJ, Sánchez-Hernández JP, Román-Rangel E (2021) Convolutional Neural Network-Component Transformation (CNN-CT) for Confirmed COVID-19 Cases. Math Comput Appl 26: 29.

8. Canul-Reich J, Frausto-Solís J, Hernández-Torruco J (2017) A Predictive Model for Guillain-Barré Syndrome Based on Single Learning Algorithm. Computational and mathematical methods in medicine.

9. Dawkins R (2016) The Selfish Gene. $40^{\text {th }}$ Edition, Oxford University Press.

10. Boulpaep EL, Boron WF (2017) Medical Physiology. $3^{\text {rd }}$ Edition, Elsevier.

11. Kotchen T (2018) Hypertensive Vascular Disease. In: Fauci AS, Longo DL, Kasper DL, Jameson JL, Loscalzo J, et al. (eds) Harrison's Principles of Internal Medicine: The profession of medicine. $19^{\text {th }}$ Edition, McGraw-Hill Education, US0041.

12. Giles RV, Evett JV, Liu C (1994) Schaum's Outline of Theory and Problems of Fluid Mechanics and Hydraulics. McGraw-Hill Education, USA.

13. Von Bertalanffy L (2015) General System Theory: Foundations, Development, Applications. George Braziller Inc.

14. Potter MC, Wiggert DC (2021) Schaum's Outline of Fluid Mechanics, $2^{\text {nd }}$ edition. McGraw-Hill Education, USA.
15. Hughes W, Brighton JA, Winowich N (1999) Schaum's Outline of Fluid Dynamics. McGraw-Hill Education, USA.

16. Kumar V, Abbas A, Aster J (2020) Robbins and Cotran: Pathological Basis of Disease. Elsevier, Canada.

17. Lehninger (2017) Principles of Biochemistry. $9^{\text {th }}$ Edition, WH Freeman, USA.

18. Atkins P, de Paula J (2010) Atkins' Physical Chemistry. $9^{\text {th }}$ Edition, Oxford University Press, Great Britain.

19. Thorne KS, Blandford RD (2017) Modern Classical Physics: Optics, Fluids, Plasmas, Elasticity, Relativity, and Statistical Physics. Princeton University Press, United Kingdom.

20. Shannon C, Weaver W (1949) The Mathematical Theory of Communication. University of Illinois Press, The University of Michigan, USA.

21. Neuhauser C (2004) Calculus for Biology and Medicine. $2^{\text {nd }}$ Edition, Pearson Prentice Hall, USA.

22. Jeffrey RC (1965) The Logic of Decision. $2^{\text {nd }}$ Edition, McGraw-Hill, The University of Michigan.

23. Giroux É (2015) Epidemiology and the bio-statistical theory of disease: a challenging perspective. Theor Med Bioeth 36: 175-195.

24. Mark DBY, Wong JB, en Jameson J (2018) The Practice of Medicine. In: Fauci AS, Longo DL, Kasper DL, Jameson JL, Loscalzo J, et al. (eds) Harrison's Principles of Internal Medicine: The profession of medicine. $2^{\text {nd }}$ Edition, McGraw-Hill Education.

25. Lamothe $M$, Lamothe $N$, Lamothe $D$, Lamothe PA (2017) La tragedia bayesiana desde la iatrogenia clínica hasta la biotecnología. Revista Médica Del Instituto Mexicano Del Seguro Social 55: 641-659.

26. Lamothe $\mathrm{N}$, Lamothe $\mathrm{M}$, Lamothe $\mathrm{D}$, Alonso-Altamirano $\mathrm{A}$, Lamothe PA (2019) Bayesian Tragedy and Categorical Medical Error in Prostate Cancer. Glob 1: J Urol 20-28.

27. Poston T, Stewart I, Jeffrey A (1978) Catastrophe theory and its applications. Pitman, USA.

28. Lamothe PJ 2007) Reforma de los Estados Democráticos y de los Oclócratas. México: Primer Mandante Epistemócrata de los Estados Unidos Mexicanos.

29. Brengelmann GL (2019) Venous return, mean systemic pressure and getting the right answer for the wrong reason. Ann Transl Med 7: 185.

30. Parati G, Bilo G, Mancia G (2004) Blood pressure measurement in research and in clinical practice: recent evidence. Curr Opin Nephrol Hypertens 13: 343-57.

31. James GD, Gerber LM (2018) Measuring arterial blood pressure in humans: Auscultatory and automatic measurement techniques for human biological field studies. Am J Hum Biol 30.

32. Herman IP (2007) Physics of the Human Body. Biol Med Physics Biomed Engineer, Springer.

33. Serway RA, Beichner RJ (2000) Physics for Scientists and engineers. $5^{\text {th }}$ Edition, Saunders College Publishing, USA.

34. Zemansky S (2008) University Physics. $12^{\text {th }}$ Edition, Pearson-Addison Wesley, USA.

35. Lipschutz S (2011) Schaums Outline of General Topology. McGrawHill Education, USA.

36. Principia Pedagogia Eléntica Heurística.

37. Russell B (1993) Introduction to Mathematical Philosophy. Dover Publications, USA.

38. Encyclopædia Britannica. 